\title{
A Three-Dimensional Numerical Model for Predicting the Weld Bead Geometry Characteristics in Laser Overlap Welding of Low Carbon Galvanized Steel
}

\author{
Kamel Oussaid, Abderrazak El Ouafi* \\ Department of Engineering, University of Quebec at Rimouski, Rimouski, QC, Canada \\ Email: *Abderrazak_elou afi@uqar.ca, Kamel.Oussaid@uqa r.ca
}

How to cite this paper: Oussaid, K. and El Ouafi, A. (2019) A Three-Dimensional Numerical Model for Predicting the Weld Bead Geometry Characteristics in Laser Overlap Welding of Low Carbon Galvanized Steel. Journal of Applied Mathematics and Physics, 7, 2169-2186.

https://doi.org/10.4236/jamp.2019.710149

Received: August 29, 2019

Accepted: October 5, 2019

Published: October 8, 2019

Copyright $\odot 2019$ by author(s) and Scientific Research Publishing Inc. This work is licensed under the Creative Commons Attribution International License (CC BY 4.0).

http://creativecommons.org/licenses/by/4.0/

(c) (i) Open Access

\begin{abstract}
Laser welding (LW) becomes one of the most economical high quality joining processes. LW offers the advantage of very controlled heat input resulting in low distortion and the ability to weld heat sensitive components. To exploit efficiently the benefits presented by LW, it is necessary to develop an integrated approach to identify and control the welding process variables in order to produce the desired weld characteristics without being forced to use the traditional and fastidious trial and error procedures. The paper presents a study of weld bead geometry characteristics prediction for laser overlap welding of low carbon galvanized steel using 3D numerical modelling and experimental validation. The temperature dependent material properties, metallurgical transformations and enthalpy method constitute the foundation of the proposed modelling approach. An adaptive 3D heat source is adopted to simulate both keyhole and conduction mode of the LW process. The simulations are performed using 3D finite element model on commercial software. The model is used to estimate the weld bead geometry characteristics for various LW parameters, such as laser power, welding speed and laser beam diameter. The calibration and validation of the 3D numerical model are based on experimental data achieved using a $3 \mathrm{~kW}$ Nd:Yag laser system, a structured experimental design and confirmed statistical analysis tools. The results reveal that the modelling approach can provide not only a consistent and accurate prediction of the weld characteristics under variable welding parameters and conditions but also a comprehensive and quantitative analysis of process parameters effects on the weld quality. The results show great concordance between predicted and measured values for weld bead geometry characteristics, such as depth of penetration, bead width at the top surface
\end{abstract}


and bead width at the interface between sheets, with an average accuracy greater than $95 \%$.

\section{Keywords}

Laser Welding, Low Carbon Galvanized Steel, Overlap Welding, Weld Bead Geometry Characteristics, 3D Modeling, Prediction Model, Finite Elements Method, Taguchi Method, ANOVA, Nd:YAG Laser Source

\section{Introduction}

The reduction of energy consumption and atmospheric pollution as well as the improvement of safety have led the automotive industry reconsider their design methods in order to decrease the weight of vehicles by using high performance materials. The tailored welded banks are now the major components constituting the new vehicle body. This design approach aims to optimize the weight of the vehicle structure by joining sheets from various nuances of high resistance material and different thicknesses. Therefore, the quantity of welds in the car body was more than doubled in the last years. In these conditions, the aptitude of the welds to resist to diverse solicitations remains the main concern of engineers. This aptitude is conditioned largely by the weld cross section geometry characteristics [1]. The identification of the laser parameter adjustments that lead to desired welds characteristics, without being forced to use the traditional and fastidious trial and error procedures, requires accurate and robustly predictive modelling approaches.

The modeling of laser welding has evolved through several stages, starting with fundamental heat equations based simple analytical models to the most complex numerical models taking into account practically all physical phenomena involved in the welding process [2]-[7]. The modeling of the heat source is one of the key elements in the evolution of laser welding models. Various modeling investigations reveal strong and direct correlation between the resulted thermal field and adopted heat source model. The first heat source model for welding was proposed by Rosenthal in 1946 where the heat source was presented in the form of a point moving along a semi-infinite work piece [8]. This model can be applied to simulate the welding of thick parts and also for surface heat treatment by laser. Using Rosenthal solution, Friedman developed in 1975, a modeling approach for estimating temperatures, stresses and distortions resulting from the welding process, using finite element method applied to butt joint welding [9]. Ashby and Easterling proposed a model where the heat source is simulated to a line source moving parallel to the surface. This model is extensively used in surface heating [10]. A double ellipsoid heat source developed by Goldak is used to simulate the deep-penetration welding [11]. This type of heat source model is used by several studies of arc welding, laser welding and laser heat treatment [12] [13] [14]. In the majority of cases, Gaussian heat sources 
presented the best option especially for laser welding [15]. Gaussian rotary volumetric heat source model proposed to simulate the heat input of laser energy in a finite element thermal analysis of laser welding of galvanized high-strength steel in a zero-gap lap joint configuration produced good results for the weld pool size prediction [13]. Models using the same type of heat source provided better results in the temperature fields estimation compared to other types of heat sources [14].

More recently, the combination of two types of heat sources, such as Gaussian conical combined with cylindrical heat source is proposed [16]. Nail head heat source resulting from the combination of point and line sources is used to describe the keyhole formation [2]. Wang proposed another model using a polynomial heat source for welding based on a Gaussian heat density distribution, by combining disc source for surface heating and polynomial equation for volumetric penetration [3]. Chande and Mazumder also investigated moving Gaussian heat source in a 3D laser welding modeling using finite differences numerical technique [4]. Despite the relatively good results obtained, the models performance remains quite limited. The advent of finite element computing software offered the possibility to build multi-physics and complex models integrating diverse interacting phenomena in the welding process. This permitted the development of many useful models to understand the evolution of welds formation and to identify the effects of this evolution on the quality of the resulting welds. As examples, the thermo-hydraulic 2D models developed to simulate the keyhole formation including the melting and vaporization of the metal [5] or to understand the evolution of the liquid/gas interface during pulsed laser welding [6].

Another study reported that convection heat transfer plays a very important role in the welding process and considered the most important factor influencing the shape and the geometry of the weld cross-section [16]. It is also reported in this study that convection heat transfer may be responsible for certain defects, such as variable penetration and lack of fusion. A hydrodynamic laser welding model including the effect of recoil pressure on the flow of molten metal is proposed reveal that the convective heat transfer induced by the recoil pressure is important for the laser absorption [17]. Chan investigated the flow in a molten pool generated by the laser by taking into account the convection of Marangoni [18]. The Marangoni phenomenon modifies the characteristics of the melting and solidification process, and makes the melt wider and shallower. The thermal properties of the material are also significant factors in the formation and shape of the melting pool [19]. The prediction of the mechanical characteristics of the welds does not always require complex models. In a detailed literature review, Mackwood and Crafer indicated that the thermal models are often sufficient and efficient in the case of laser welding [9]. However, in most studies, the heat sources are used in keyhole mode and conduction mode separately, and in most cases, the models are applied on laser welding in butt joint configuration.

Oussaid et al. conducted an experimental investigation to evaluate the effects 
of various laser welding parameters on the welding quality [20]. Laser power, welding speed, laser fiber diameter, gap between sheets and sheets thickness are combined and used to evaluate the variation of three geometrical characteristics of the weld: penetration depth, bead width at the surface and bead width at the interface. In this study, various improved statistical tools are used to investigate the effects of the welding parameters on the weld quality and to identify the possible relationship between these parameters and the geometrical characteristics of the weld. The investigation results reveal that there are many options can be considered for building an efficient welds quality prediction model. Results achieved using an artificial neural network (ANN) based simplified model demonstrated promising model performances.

Indeed, when a fast and efficient prediction model is needed, ANN offers many advantages especially in the case of computationally intensive predictions and real-time applications where numerical models are very slow and not adapted. ANN models have been used with success to model many welding process. However, ANN model can accurately predict the weld geometry as well as the change in weld pool profiles like between conduction mode and keyhole mode only if trained with good and appropriate data. Moreover, producing an accurate and flexible ANN model requires very large data to ensure efficient ANN learning and validation processes. On the other hand, the generation of the needed data using experiment is relatively long and expensive. Therefore, experimentally validated 3D finite element method based models can be used to generate acceptable and cost effective data.

The present paper describes the development of a 3D numerical model to be used for generating the additional data needed to build the most accurate, flexible and efficient ANN based model for predicting the weld bead geometry characteristics in laser overlap welding of low carbon galvanized steel. An integrated approach combining 3D numerical modeling and experimental validation is proposed to produce the most consistent predictions. The welding process simulation is carried out by 3D finite element model using Comsol Multiphysics software. The numerical modelling is built on simple heat transfer model based on a moving heat source in a finite medium volume to evaluate the temperature field, and thus to estimate the melting zone dimensions and the weld geometry characteristics for various welding parameters and conditions. The model is based on an improved adaptive 3D heat source used to simulate both key-hole and conduction laser welding process mode. The volumetric heat source is calibrated using specific factors defined as function of the laser parameters to adapt respectively the weld bead width and the absorption depth of the laser beam. The latent heat of fusion is taken into account by adapting the material temperature dependent specific heat in the temperature range situated between solidus and liquidus. The calibration and validation of the model are achieved using experimental data produced on a commercial $3 \mathrm{~kW}$ Nd:Yag laser system performed according to a structured experimental design and confirmed statistical analysis tools. The results reveal that the $3 \mathrm{D}$ numerical model is able to provide not only 
a consistent and accurate prediction of the weld bead geometry characteristics under variable welding parameters and conditions but also a comprehensive analysis of the average effects of the welding parameters on the weld quality. The results show great concordance between predicted and measured values of the weld characteristics.

The paper is organized in four parts as follows. The first presents an introduction, a brief review and the objectives of the study. The second outlines succinctly the numerical method, describes the model, the governing equations and the simulation parameters and conditions. The third discusses the numerical and experimental results. The fourth presents the conclusion of the work and outline the potential direction of future research.

\section{Method and Materials}

\subsection{Model Description}

The 3D simulation model of the laser welding process in overlap joint configuration consists to irradiate two overlapped low carbon galvanized steel sheets with respective thickness of 1 and $2 \mathrm{~mm}$, as presented in Figure 1. The laser beam directed to the upper surface moves along a straight line, which becomes the axis of the performed weld bead. The laser beam is represented as a moving $3 \mathrm{D}$ volumetric heat source with a conical Gaussian distribution so that the integral of the air under the heat distribution curve equals to a unit as illustrated in Figure 2. The heat source model expressed as function of the laser welding parameters and the material properties is used to determine the size and the shape of the weld cross section. This representation allows to evaluate the weld bead geometry characteristics variation as function of the laser welding parameters [8].

The proposed model is however built under various simplifying assumptions such as: 1) the influence of zinc vapor diffusion on the thermal properties of

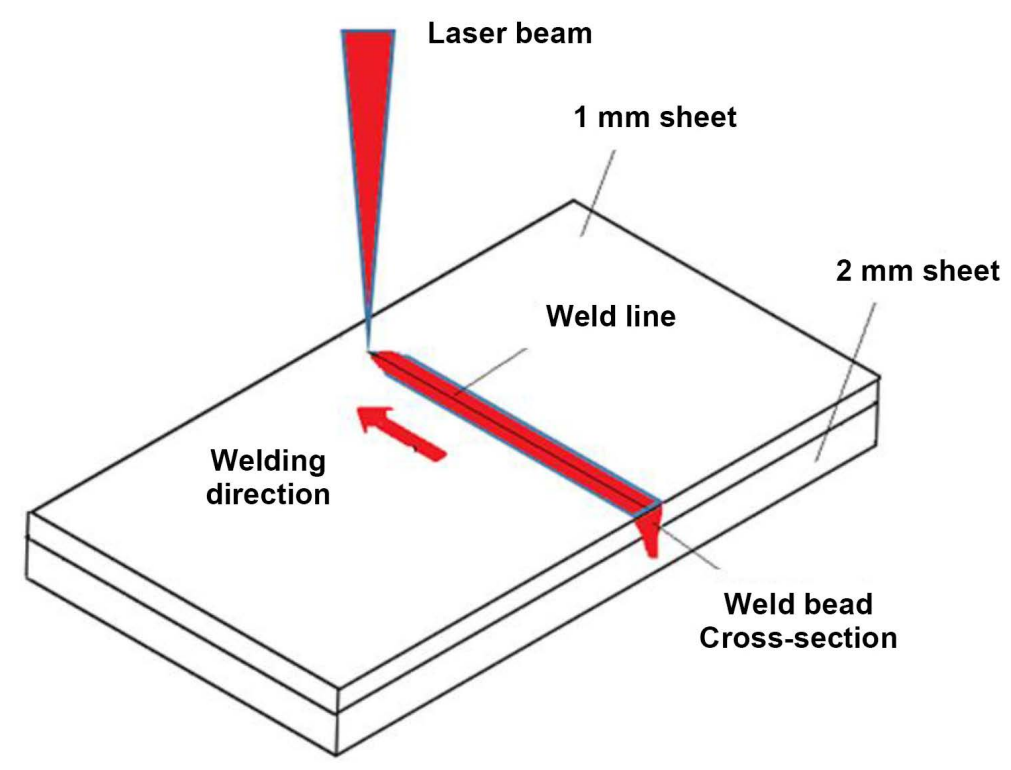

Figure 1. Overlap laser welding model description. 


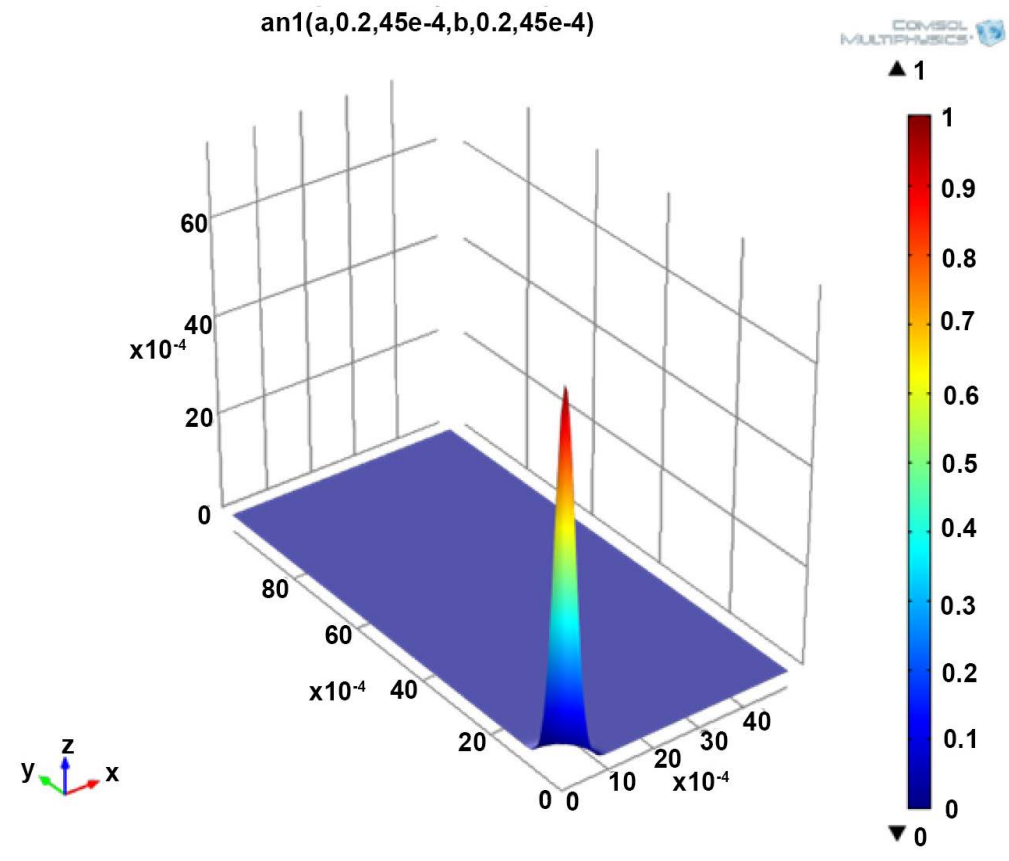

Figure 2. Gaussian distribution of laser beam power.

weld zone is ignored. 2) The experimental investigations revealed a relatively limited effect of the gap size on different weld geometric characteristics. The maximum observed contribution of the gap in these characteristics variation represents approximately 5\%. Therefore, the gap size is not considered as variable in the present model. 3) The material is considered homogeneous and isotropic. 4) The welded parts are considered free from any geometrical imperfection, and finally 5) Fluid flows, Marangoni effect and the latent heat of vaporization are not considered in order to simplify the model and to avoid long simulations.

\subsection{Heat Transfer Formulation}

The proposed model is based on conduction heat transfer including melting phase change. Equation (1) called Fourier's second law, describes the transient heat conduction in the solid. Solving this well-known equation permit to obtain the temperature field distribution in welded sheets at specific time and spatial coordinates.

$$
\rho C_{P} \frac{\mathrm{d} T}{\mathrm{~d} t}=k \nabla^{2} T+Q(x, y, z, t)
$$

where $\rho, k, C_{p}$ and $Q$ Denote respectively the material density, the thermal conductivity, heat capacity and the heating power per unit volume.

The melting phase change is included into the model both in term of latent heat of fusion and the temperature dependant properties. The enthalpy method is used to model the phase transition by modifying the temperature dependent heat capacity as denoted in Equation (2) and illustrated in Figure 3 [6]. 


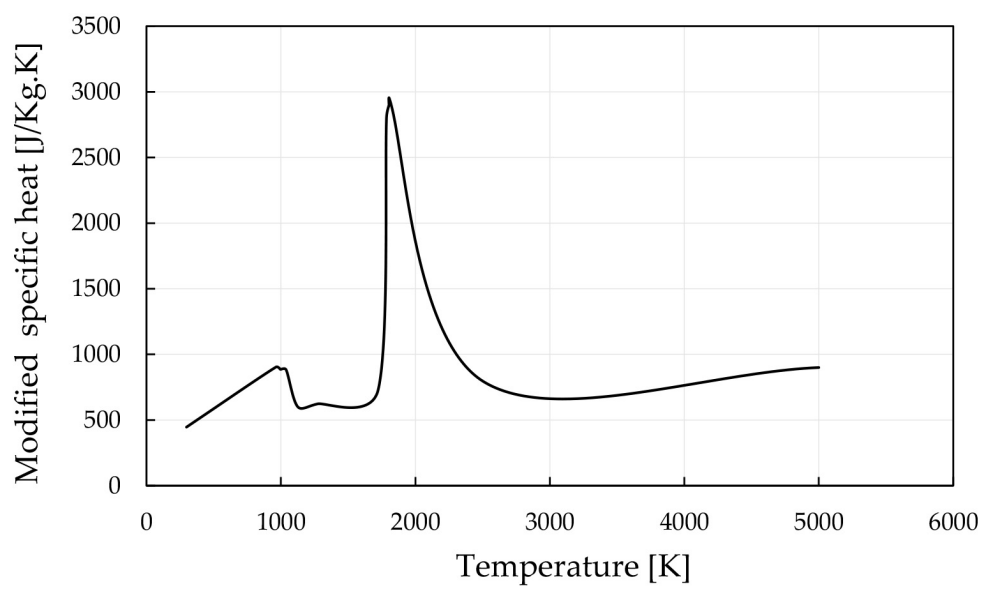

Figure 3. Temperature dependent specific heat including the enthalpy of fusion.

$$
C_{P}=C_{P}^{*}(T)+\frac{1}{\Delta T \sqrt{ } \pi} \mathrm{e}^{-\frac{T-T_{f}}{\Delta T^{2}}} L_{f}
$$

With $T_{f}$ the melting point, $L_{f}$ tent heat of fusion and $\Delta T$ a temperature range of solid/liquid phase change set to $72 \mathrm{~K}$.

\subsection{Boundary and Initial Conditions}

At the initial time, sheets temperature is uniform and set at the room temperature T_0 $=295 \mathrm{~K}$. Heat exchange between the welded parts and their external environment is integrated into the numerical model as a heat loss, which is expressed by convection and radiation. The convection occurs in the top surface and frontal surfaces. The convection is expressed as:

$$
Q_{\text {conv }}=h\left(T-T_{0}\right)
$$

With $h$ the natural convection coefficient and $T_{0}$ the room temperature. The radiation is occurred at the top surface and expressed by the Stephan Boltzmann law:

$$
Q_{\text {rad }}=\sigma \varepsilon\left(T^{4}-T_{0}^{4}\right)
$$

With $\sigma$ Stephan-Boltzmann constant and $\varepsilon$ the material emissivity.

The bottom surface is supposed thermally insulated according to the following equation:

$$
-n(k \nabla T)=0
$$

Since the geometry and laser beam are symmetric across the y-axis, the symmetry boundary condition suggests that only half of the geometry is modeled. This symmetry simplification ignores the laser beam misalignment during welding and the geometrical imperfections of the parts. The symmetry simplification has drastically reduced the computational time. Figure 4 is a representation of the thermal transfers and boundary conditions applied to the welded sheets. 


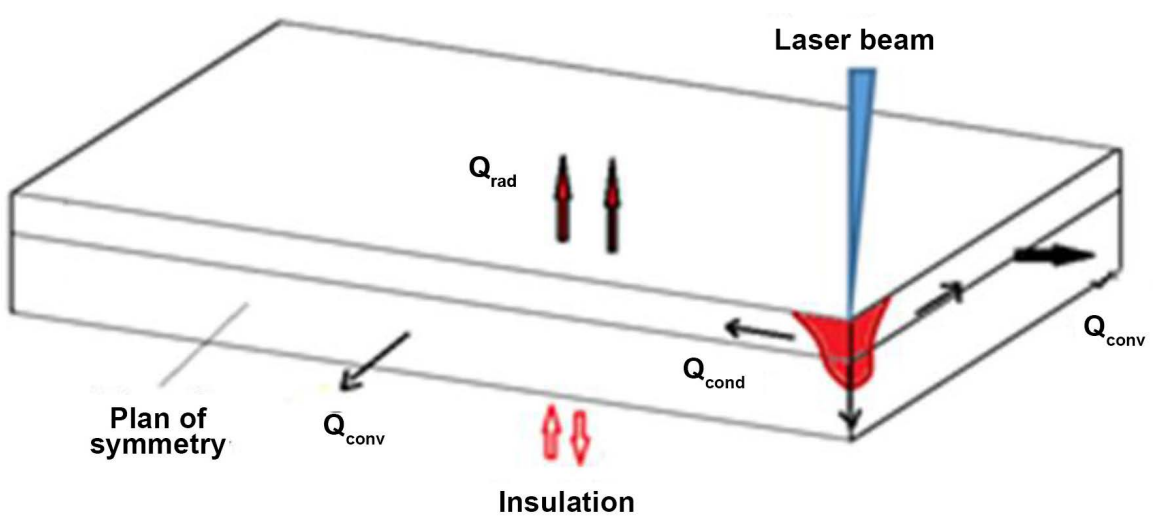

Figure 4. Heat transfer modes and boundary conditions applied to the laser welding process.

\subsection{Heat Source Modeling}

The identification of adequate heat source is the most important step in welding process model building. According to the literature, a conical heat source with Gaussian distribution is the simplest and the most appropriate for predicting the shape of the laser weld bead cross-section [21]. Depending on the density of laser energy and the interaction time with the metal parts, two welding modes are possible: the conduction mode and the keyhole mode. The conduction mode occurs before reaching the vaporization temperature of the metal. In this mode, the energy is absorbed directly by the metal and dissipated by conduction in all directions, thus favouring round and wide welds with small penetration. In keyhole mode, which is characterized by a high energy density and a sufficiently slow interaction time, the irradiated surface of the metal reaches rapidly the vaporization temperature. These vapours create an evacuation channel, which allows a better and deeper absorption of the laser beam energy, thus producing deep and sharp v-welds [22].

In General, to differentiate between the two welding modes during modeling, simply assign a heat source to each mode. A 2D surface heat source (Equation (6)) to the conduction mode and a $3 \mathrm{D}$ volumetric heat source (Equation (7)) to the keyhole mode. The transition between the two modes must take place at the vaporisation temperature, but this increases the model complexity, because it can happen, for the same laser conditions, to start the simulation with $2 \mathrm{D}$ heat source and finish with 3D heat source.

$$
\begin{aligned}
& Q(x, y, t)=\frac{Q_{0} A(1-R)}{2 \pi r^{2}} \cdot \exp \left(-\frac{\left(x-x_{0}\right)^{2}}{2 r^{2}}-\frac{(y-v t)^{2}}{2 r^{2}}\right) \\
& Q(x, y, z, t)=\frac{Q_{0} A(1-R)}{2 \pi r^{2}} \cdot \exp \left(-\frac{\left(x-x_{0}\right)^{2}}{2 r^{2}}-\frac{(y-v t)^{2}}{2 r^{2}}-A_{c}|z|\right)
\end{aligned}
$$

Since the difficulty to set the transition threshold according to laser parameters, an adaptive $3 \mathrm{D}$ heat source, moving in the $\mathrm{y}$ axis direction, is used to simulate both keyhole and conduction mode (Equation (8)). This volumetric heat source 
is calibrated by introducing two coefficients ( $m$ and $n$ ) to adapt respectively the weld bead width and the absorption depth of the laser beam. These coefficients are related to the laser parameters with the most significant contribution to the variation of weld characteristics [20].

$$
Q(x, y, z, t)=\frac{Q_{0} A(1-R)}{2 \pi r^{2}} \exp \left(-\frac{\left(x-x_{0}\right)^{2}}{(m r)^{2}}-\frac{(y-v t)^{2}}{2 r^{2}}-n A_{c}|z|\right)
$$

where $Q_{0}, v, A, R$ and $r$ denote respectively laser power, welding speed, material absorptivity, material reflectivity and laser beam radius.

The coefficients $m$ and $n$ are estimated as function of the laser parameters using the following empirical relationships.

$$
\begin{array}{r}
-n(k \nabla T)=0 m=1.194-17310^{-6} Q 0[W]+18.33 v\left[\frac{m}{s}\right]+649 d[m] \\
n=0.565-8310^{-6} Q 0[W]+9.44\left[\frac{m}{s}\right]+123 d[m]
\end{array}
$$

\subsection{Geometry and Material Properties}

The geometry is discretized using an extremely refined tetrahedral mesh at the neighborhood of the weld line and large mesh elements in the rest of the geometry. A mesh convergence study is conducted to determine the optimal mesh size, by simulating the welding process using the same laser parameters setting (2500 [W] laser power, $55[\mathrm{~mm} / \mathrm{s}]$ welding speed and $395[\mu \mathrm{m}]$ laser beam diameter) and different mesh sizes around the weld line.

As illustrated in Figure 5, the temperature is evaluated at a specific time in two points, located respectively in the top surface and the interface of the melting pool, according to different mesh sizes. Convergence curves show that temperatures become unchanged for mesh value less than $0.15 \mathrm{~mm}$, otherwise, temperatures fluctuate due to errors in accuracy and truncation. To reduce the calculation time, the width and length of the geometry are reduced, on condition that the weld attributes are evaluated in the area where the welding process has reached its stationary state. The final dimensions of the meshed geometry are illustrated in Figure 6.

In order to validate the proposed model, typical ASTM A635 CS galvanized steel sheets with A40 coating type commonly used in the automotive industry are used to perform the overlap joint welds. The temperature dependant properties of this low carbon steel, which are density, thermal conductivity and specific heat, integrated in model are summarized in Table 1. The material constants are presented in Table 2.

\subsection{Laser Parameter Setting and Model Validation}

A series of simulations and tests of validation were carried out simultaneously, according to comprehensive and structured experimental design. As indicated in Table 3, three levels are selected for each of the three laser parameters (laser 


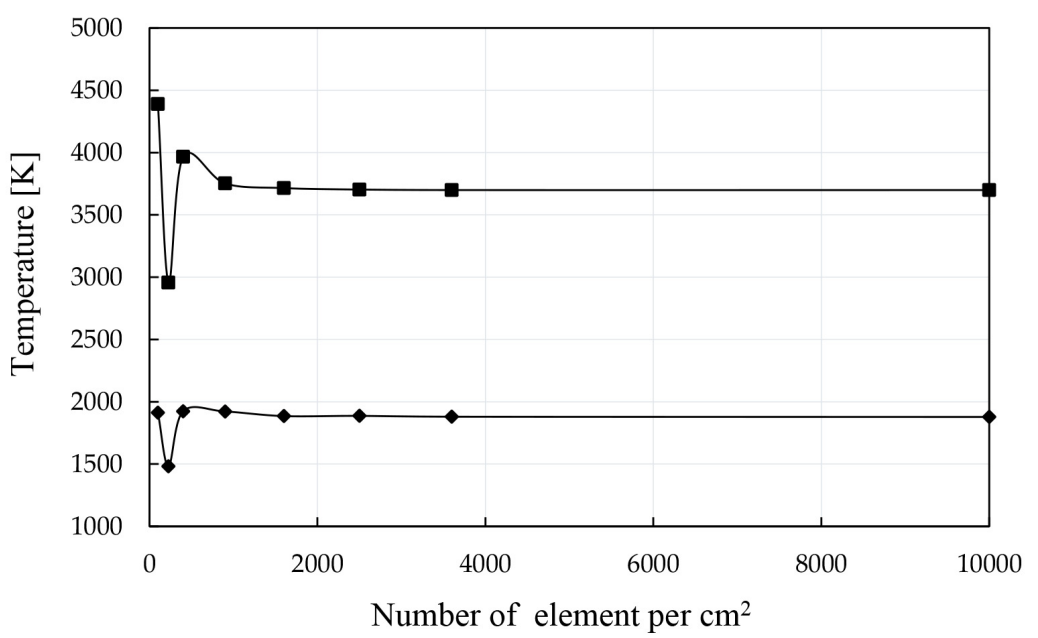

Figure 5. Mesh convergence study.

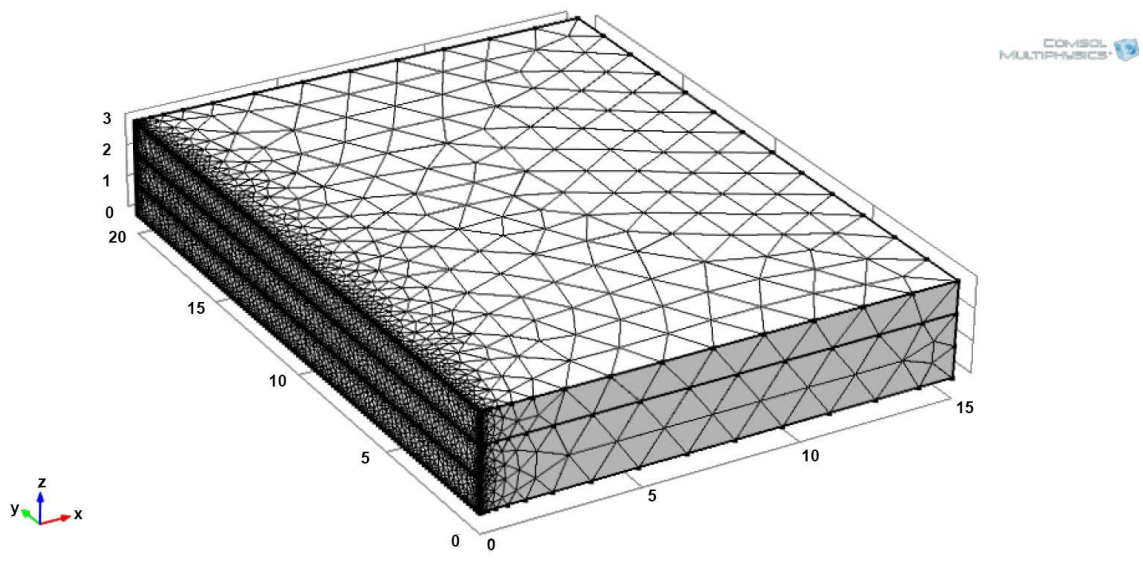

Figure 6. Finite element mesh of weld specimen.

Table 1. Temperature dependent properties of low carbon steel.

\begin{tabular}{cccc}
\hline $\begin{array}{c}\text { Temperature } \\
{[\mathrm{K}]}\end{array}$ & $\begin{array}{c}\text { Density } \\
{\left[\mathrm{kg} / \mathrm{m}^{3}\right]}\end{array}$ & $\begin{array}{c}\text { Specific heat } \\
{[\mathrm{J} /(\mathrm{kg} \cdot \mathrm{K})]}\end{array}$ & $\begin{array}{c}\text { Thermal conductivity } \\
{[\mathrm{W} /(\mathrm{m} \cdot \mathrm{K})]}\end{array}$ \\
\hline 298 & 7863 & 446 & 74.7 \\
962 & 7639 & 903 & 35.7 \\
996 & 7648 & 886 & 34.1 \\
1039 & 7647 & 882 & 32.2 \\
1126 & 7661 & 600 & 28.3 \\
1273 & 7587 & 623 & 29.6 \\
1723 & 7317 & 729 & 33.6 \\
1785 & 7287 & 738 & 34.2 \\
1804 & 7132 & 785 & 34.8 \\
1806 & 7030 & 817 & 35 \\
2503 & 6449 & 795 & 35
\end{tabular}


Table 2. Constant properties of low carbon steel.

\begin{tabular}{cccc}
\hline Property & Symbol & Value & Unit \\
\hline Temperature liquidus & $T_{L}$ & 1806 & $\mathrm{~K}$ \\
Temperature solidus & $T_{S}$ & 1734 & $\mathrm{~K}$ \\
Latent heat of fusion & $L_{f}$ & 244 & $\mathrm{~kJ} / \mathrm{kg}$ \\
Material emissivity & $\mathcal{E}$ & 0.6 & \\
Material Absorptivity & $A$ & 800 & $1 / \mathrm{m}$ \\
Material reflectivity & $R$ & 0.3 & - \\
\hline
\end{tabular}

Table 3. Welding process parameters.

\begin{tabular}{cccccc}
\hline Laser Parameter & Symbol & Unit & Level 1 & Level 2 & Level 3 \\
\hline Power & Q0 & $\mathrm{W}$ & 2000 & 2500 & 3000 \\
Speed & $\mathrm{v}$ & $\mathrm{mm} / \mathrm{s}$ & 40 & 55 & 70 \\
Diameter & $\mathrm{d}$ & $\mu \mathrm{m}$ & 300 & 395 & 490 \\
\hline
\end{tabular}

power, welding speed and laser beam diameter). These parameters and levels are fixed following a series of preliminary tests [20]. Both for simulations and experiments, the weld cross section dimensions are measured in the stationary state zone to evaluate three weld geometry characteristics: depth of penetration (DOP), bead width at the top surface (WS) and bead width at the interface between sheets (WI). The cutting plane is located in the middle of the work piece and simulation results are evaluated at time $t=L / 2 \mathrm{v}$.

The total computation time depends on the welding speed: time_end $=L / V$, while the time step depends on the laser beam diameter, such the position of the laser beam at time $t_{-} i$ is located at a distance $s=2 / 3{ }^{*} d$ from its previous position, ie at time $t_{-}(i-1)$.

Where $L$ is the model geometry length, $d$ the laser beam diameter and $v$ the welding speed.

\section{Results and Discussions}

The contours of the weld cross sections are determined from the temperature fields based on the location of points reaching the liquidus temperature. The weld penetration depth and the weld seam width, respectively at the surface and at the interface are measured on the cross sections of the weld using an adapted Matlab indexing algorithm. Figure 7 and Figure 8 show examples of typical simulation and experimental results. The predicted bead characteristics are then compared to the measurements obtained from the experiments. The model performance is evaluated using various statistical criteria estimating the prediction errors.

A number of methods are available to evaluate the models performance by estimating the prediction errors. It is generally recommended to use several criteria to 


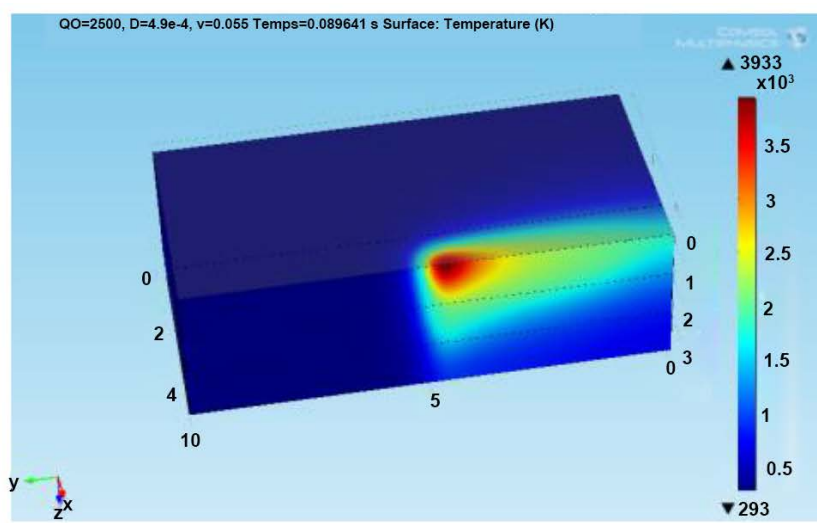

(a)

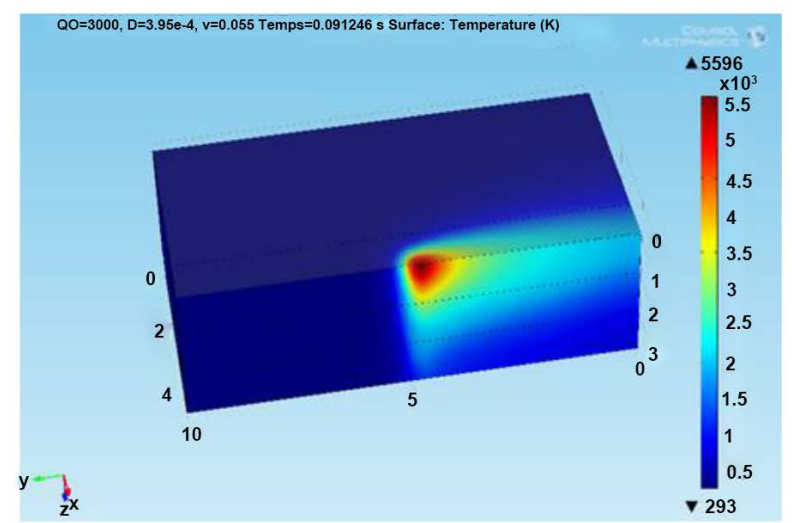

(b)

Figure 7. Simulation results for (a) $P=2500 \mathrm{~W}, \mathrm{~V}=55 \mathrm{~mm} / \mathrm{s}$ and $\mathrm{D}=490 \mu \mathrm{m}$, and (b) $\mathrm{P}=3000 \mathrm{~W}, \mathrm{~V}=55 \mathrm{~mm} / \mathrm{s}$ and d $=395$ $\mu \mathrm{m}$.
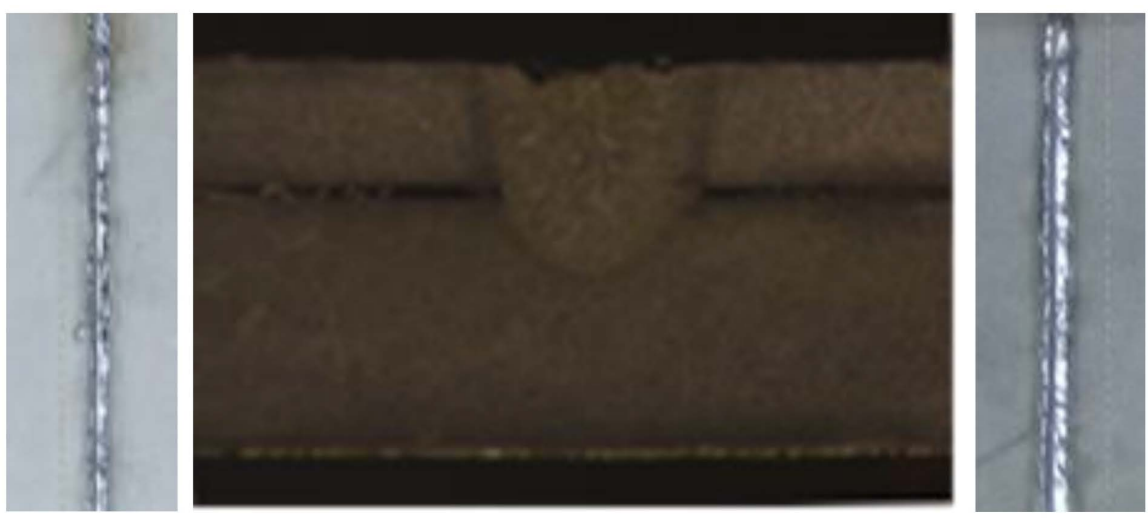

Figure 8. Typical cross section shape of overlap welded galvanized sheets.

obtain a satisfactory prediction error estimate. The following four traditional estimates from forecasting techniques are often used: 1) the coefficient of determination (R2), 2) the Mean Absolute Error $(M A E), 3)$ the Mean Absolute Percent Error $(M A P E), 4)$ the Mean Root Squared Error $(M R S E)$, and 5) the Relative Mean Root Squared Error (RMRSE). They can be defined mathematically as:

$$
\begin{gathered}
R^{2}=1-\frac{\sum_{i=1}^{n}\left(y_{i}-\hat{y}_{i}\right)^{2}}{\sum_{i=1}^{n}\left(y_{i}-\bar{y}\right)^{2}} \\
M A E=\frac{1}{n} \sum_{i=1}^{n}\left|y_{i}-\hat{y}_{i}\right| \\
A P E=\left(\frac{1}{n} \sum_{i=1}^{n}\left|\frac{y_{i}-\hat{y}_{i}}{y_{i}}\right|\right) 100(\%) \\
\text { MRSE }=\frac{1}{n} \sqrt{\sum_{i=1}^{n}\left(y_{i}-\hat{y}_{i}\right)^{2}} \\
\text { RMRSE }=\frac{M R S E}{\bar{y}} 100(\%)
\end{gathered}
$$


The combination of these statistical tools provides a very clear picture of the model performance by providing a satisfactory prediction error estimates. The performance of the model, based on the selected five criteria, is presented at Table 4 . The results reveal a good agreement between predicted and measured bead geometry characteristics. The model provides an $\mathrm{R}^{2}$ less than $90 \%$ the three weld characteristics. $\mathrm{R}^{2}$ reaches $96 \%$. The maximum observed MAPE remains less than $7.5 \%$ representing about $7 \%, 2.5 \%$ and 7.5 for DOP, WS and WI respectively. The maximum observed RMRSE remains less than $3.5 \%$ representing $3.04 \%, 1.09 \%$ and 3.32 for DOP, WS and WI respectively. The best model performance is obtained for WS with prediction errors 3 times lower than for DOP and WI. The highest errors are obtained for WI. This is explained by slight variation of the gap during the experiments. Globally, with such good results, the model is considered adequate to be used without difficulty in predictive strategies.

Another dimension of the model evaluation consists to compare the laser parameters effects on the weld bead geometry characteristics extracted from ANOVA performed on the $\mathrm{L}_{9}$ experimental data with those extracted from ANOVA performed on simulation data. The simulation data are generated from a structured $\mathrm{L}_{27}$ factorial design using the same parameter as in the experimentation. The choice of $\mathrm{L}_{27}$ is motivated by the possibility to evaluate the effect of the laser parameters interaction on the variation weld bead geometry characteristics. The interaction cannot be evaluated by a fractional design.

Table 5 summarises the ANOVA results based on the simulation data. The laser parameters effects, in term of percentage contributions of the $(\% \mathrm{C})$, on the variation of the three weld characteristics are practically the same as in the case of the experimental data. Figure 9, Figure 10 and Figure 11 illustrate the comparison of the \% C obtained respectively from an L9 experimental data, an 19

Table 4. Performance of the prediction of weld geometry characteristics.

\begin{tabular}{cccccc}
\hline & $\mathrm{R}^{2}$ & MAE & MAPE & MRSE & RMRSE \\
\hline DOP & $90.94 \%$ & 146.33 & $6.94 \%$ & 60.22 & $3.04 \%$ \\
WS & $96.09 \%$ & 30.56 & $2.44 \%$ & 13.84 & $1.09 \%$ \\
WI & $94.12 \%$ & 102.11 & $7.28 \%$ & 40.75 & $3.32 \%$ \\
\hline
\end{tabular}

Table 5. Simplified ANOVA results for DOP, WS and WI.

\begin{tabular}{cccccccc}
\hline \multirow{2}{*}{ Source } & DF & \multicolumn{2}{c}{ DOP } & \multicolumn{2}{c}{ WS } & \multicolumn{2}{c}{ WI } \\
\cline { 2 - 7 } & & \% C & F-Value & \% C & F-value & \% C & F-Value \\
\hline $\mathrm{P}$ & 2 & 28.53 & 960.01 & 47.03 & 796.22 & 28.24 & 82.13 \\
$\mathrm{D}$ & 2 & 12.61 & 424.09 & 10 & 169.25 & 22.23 & 71.45 \\
$\mathrm{~V}$ & 2 & 56.14 & 1888.73 & 40.91 & 692.63 & 45.18 & 145.23 \\
$\mathrm{P} * \mathrm{D}$ & 4 & 0.13 & 2.23 & 0.28 & 2.41 & 1.50 & 2.42 \\
$\mathrm{P} * \mathrm{~V}$ & 4 & 2.33 & 39.24 & 1.34 & 11.32 & 0.48 & 0.78 \\
$\mathrm{~V} * \mathrm{D}$ & 4 & 0.14 & 2.3 & 0.21 & 1.76 & 3.83 & 0.28 \\
Error & 18 & 0.12 & & 0.24 & & 1.24 & 100 \\
Total & 26 & 100 & & 100 & & & \\
\hline
\end{tabular}




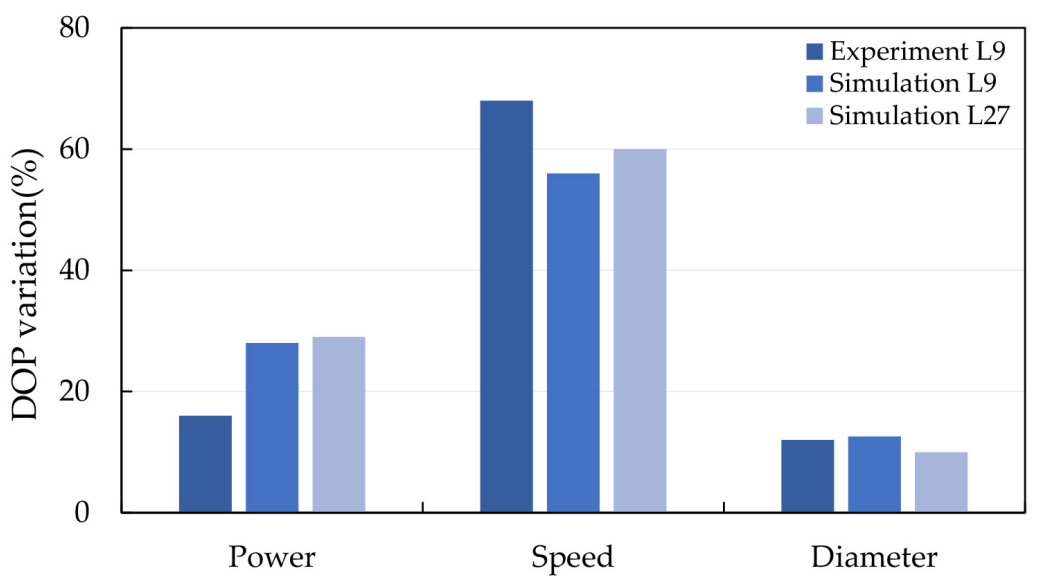

Figure 9. Laser parameters contribution to the variation of DOP.

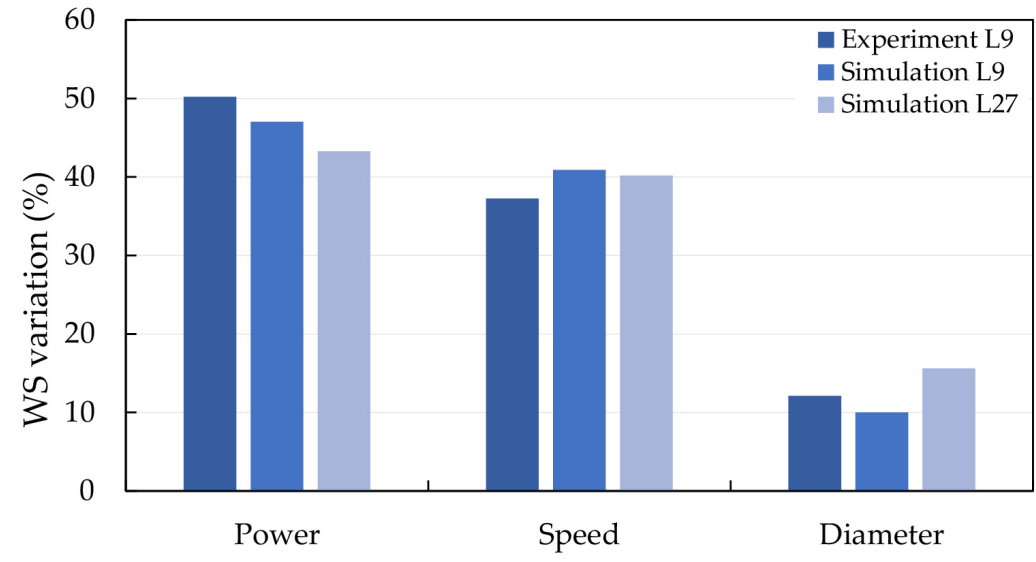

Figure 10. Laser parameters contribution to the variation of WS.

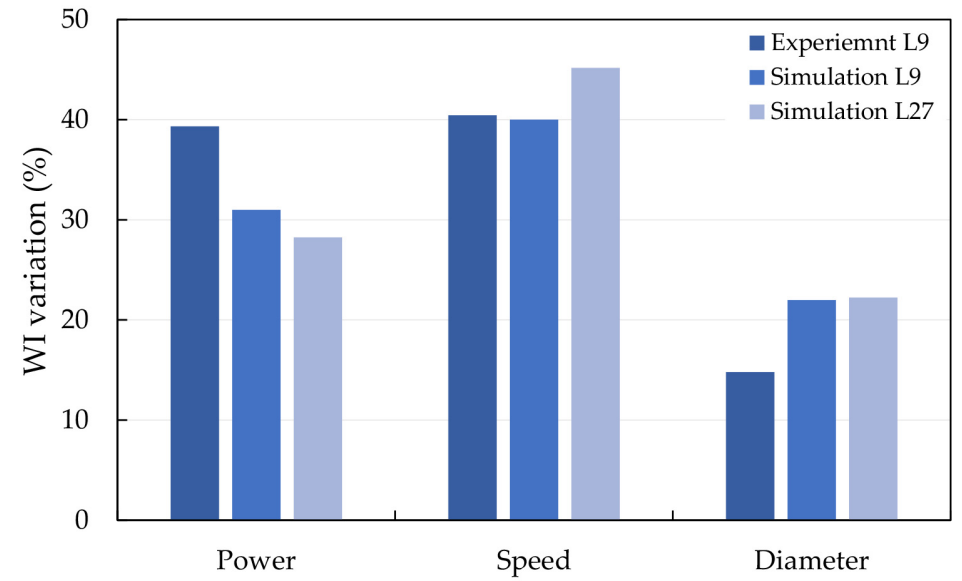

Figure 11. Laser parameters contribution to the variation of WI.

simulation data and an L27 simulation data. These graphs reveal small differences between the three designs. The largest difference (less than 10\%) is observed for the power contribution in WI variation. This is probably due to the fact of not considering the gap in the simulations. 

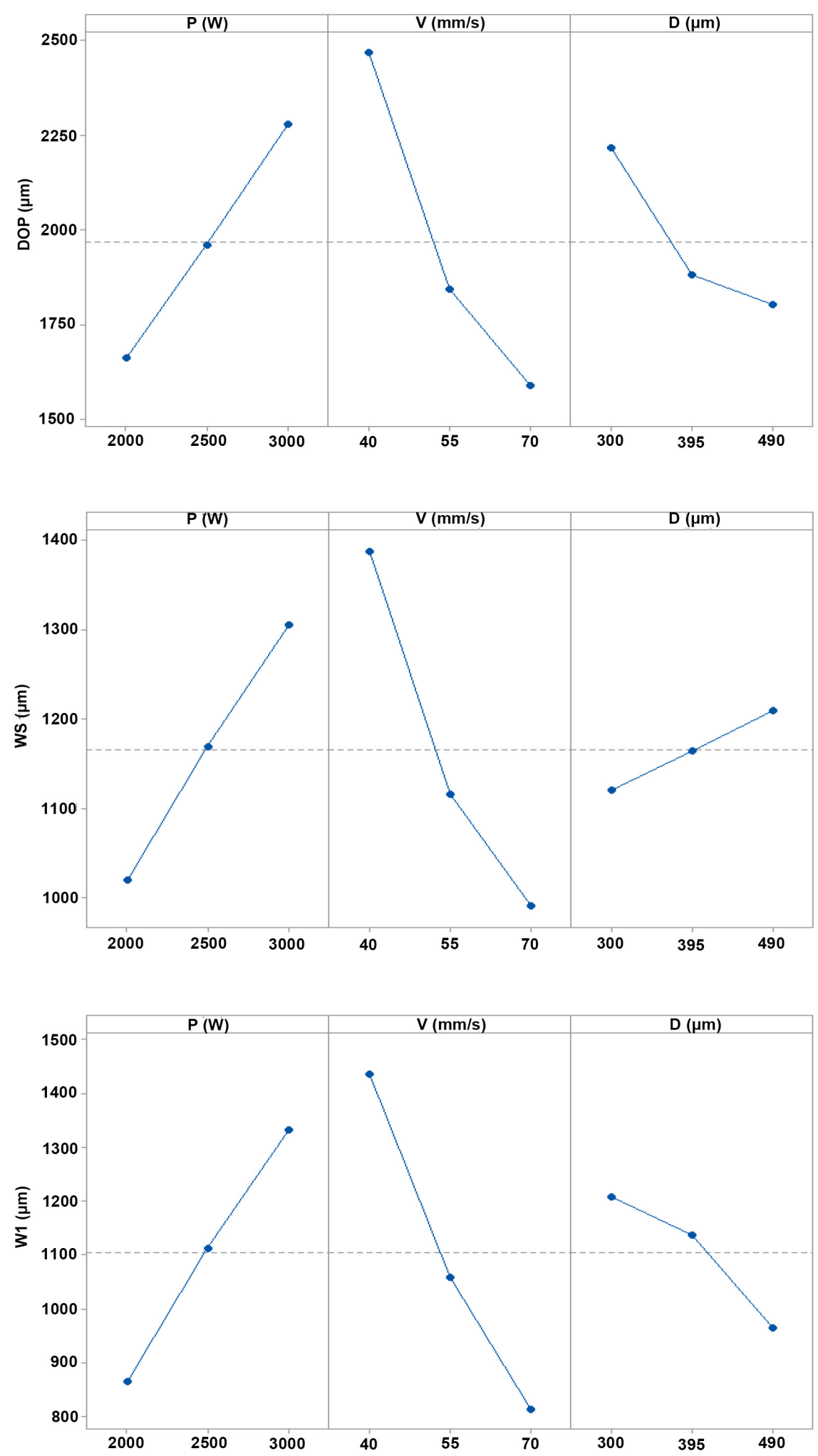

Figure 12. Effects of laser parameters on weld characteristics variation.

As established following the experimentation phase, the welding speed and the laser power are the most influential factors on the weld bead geometric cha- 
racteristics, while the laser beam diameter effect remains relatively limited. The evaluation of the laser parameters interaction shows also non-significant effects. The total contribution of all interactions does not exceed $6 \%$. It represents $2.6 \%$, $1.83 \%$ and 5.81 for DOP, WS and WI respectively. These results are validated by the graphs of effects of the laser parameters on the weld bead geometry characteristics presented in Figure 12. An F-test is conducted to confirm the laser parameters contributions and effects based conclusions.

\section{Conclusions}

The present paper presents an integrated approach for building a forecasting 3D finite element model able to predict weld bead geometry characteristics for laser welding of low carbon galvanized steel in overlap configurations. An improved adaptive 3D heat source is used for simulating both keyhole and conduction mode. The implementation of the model is supported by a heat source calibration technique using specific modelling factors defined as function of the laser parameters to adapt respectively the weld bead width and the absorption depth of the laser beam.

A commercial $3 \mathrm{~kW} \mathrm{Nd:Yag} \mathrm{laser} \mathrm{system,} \mathrm{a} \mathrm{structured} \mathrm{experimental} \mathrm{design}$ and improved statistical analysis tools are used to evaluate the modelling approach and to confirm the prediction model accuracy. Extensively numerical simulations carried out through 3D finite element method reveal great concordance between modelling and experimental results. The comparison of predicted and measured weld geometric characteristics reveals an average accuracy greater than $95 \%$. The prediction errors originate principally from experimental errors as well as from the considered assumptions. Globally, the results demonstrate that the numerical simulation can effectively lead to a consistent and accurate weld bead geometry characteristics prediction model under variable welding parameters and conditions and provide an appropriate framework for comprehensively qualitative and quantitative analysis of the effects of welding process parameters on the weld quality.

With the encouraging results obtained using this model, the laser overlap welding of low carbon galvanized steel will be the subject of additional and intensive investigations to generate more simulation and experimental data in order to develop an efficient ANN predictive modelling approach.

\section{Conflicts of Interest}

The authors declare no conflicts of interest regarding the publication of this paper.

\section{References}

[1] Ribolla, A., Damoulis, G.L. and Batalha, G.F. (2005) The Use of Nd:Yag Laser Weld for Large Scale Volume Assembly of Automotive Body in White. Journal of Materials Processing Technology, 164-165, 1120-1127.

https://doi.org/10.1016/j.jmatprotec.2005.02.104 
[2] Kazemi, K. and Goldak, J.A. (2009) Numerical Simulation of Laser Full Penetration Welding. Computational Mat. Science, 44, 841-849. https://doi.org/10.1016/j.commatsci.2008.01.002

[3] Wang, J., Han, J., Domblesky, J.P., Yang, Z., Zhao, Y. and Zhang, Q. (2016) Development of a New Combined Heat Source Model for Welding Based on a Polynomial Curve Fit of the Experimental Fusion Line. The International Journal of Advanced Manufacturing Technology, 87, 1985-1997. https://doi.org/10.1007/s00170-016-8587-3

[4] Chande, T. and Mazumder, J. (1984) Estimating Effects of Processing Conditions and Variable Properties upon Pool Shape, Cooling Rates, and Absorption Coefficient in Laser Welding. Journal of Applied Physics, 56, 1981-1986.

https://doi.org/10.1063/1.334231

[5] Courtois, M., et al. (2012) Keyhole Formation during Spot Laser Welding: Heat and Fluid Flow Modeling in a 2D Axisymmetric Configuration. Proceedings of the COMSOL Conference, Milan, 1-6.

[6] Bruyere, V., Touvrey, C. and Namy, P. (2014) A Phase Field Approach to Model Laser Power Control in Spot Laser Welding. Proceedings of the COMSOL Conference, Cambridge, 1-6.

[7] Steen, W.M. and Mazumder, J. (2010) Laser Material Processing. Springer Science \& Business Media, Berlin. https://doi.org/10.1007/978-1-84996-062-5

[8] Rosenthal, D. (1946) The Theory of Moving Source of Heat and Its Application to Metal Treatment. Transactions of the ASME, 68, 849-866.

[9] Friedman, E. (1975) Thermo-Mechanical Analysis of the Welding Process Using the Finite Element Method. Journal of Pressure Vessel Technology, 97, 206-213. https://doi.org/10.1115/1.3454296

[10] Ashby, M.F. and Easterling, K.E. (1984) The Transformation Hardening of Steel Surfaces by Laser Beams I. Hypo-Eutectoid Steels. Acta Metallurgica, 32, 1935-1948. https://doi.org/10.1016/0001-6160(84)90175-5

[11] Goldak, J., Chakravarti, A. and Malcolm, B. (1984) A New Finite Element Model for Welding Heat Sources. Metallurgical and Materials Transactions B, 15, 299-305. https://doi.org/10.1007/BF02667333

[12] Cline, H.E. and Anthony, T. (1977) Heat Treating and Melting Material with a Scanning Laser or Electron Beam. Journal of Applied Physics, 48, 3895-3900. https://doi.org/10.1063/1.324261

[13] Davis, M., Kapadia, P., Dowden, J., Steen, W.M. and Courtney, C.H.G. (1986) Heat Hardening of Metal Surfaces with a Scanning Laser Beam. Journal of Physics D: Applied Physics, 19, 1981-1997. https://doi.org/10.1088/0022-3727/19/10/024

[14] Bradley, J.R. (1988) A Simplified Correlation between Laser Processing Parameters and Hardened Depth in Steels. Journal of Physics D: Applied Physics, 21, 834-837. https://doi.org/10.1088/0022-3727/21/5/027

[15] Mackwood, A.P. and Crafer, R.C. (2005) Thermal Modelling of Laser Welding and Related Processes: A Literature Review. Optics \& Laser Technology, 37, 99-115. https://doi.org/10.1016/j.optlastec.2004.02.017

[16] Chukkan, J.R., et al. (2015) Simulation of Laser Butt Welding of AISI 316L Stainless Steel Sheet Using Various Heat Sources and Experimental Validation. Journal of Materials Processing Technology, 219, 48-59. https://doi.org/10.1016/j.jmatprotec.2014.12.008

[17] Semak, V.V., Damkroger, B. and Kempka, S. (1999) Temporal Evolution of the 
Temperature Field in the Beam Interaction Zone during Laser Material Processing. Journal of Physics D: Applied Physics, 32, 1819-1825.

https://doi.org/10.1088/0022-3727/32/15/309

[18] Chan, C., Mazumder, J. and Chen, M.M. (1984) A Two-Dimensional Transient Model for Convection in Laser Melted Pool. Metallurgical and Materials Transactions $A, 15,2175-2184$. https://doi.org/10.1007/BF02647100

[19] Bannour, S., Abderrazak, K., Mhiri, H. and Le Palec, G. (2012) Effects of Temperature-Dependent Material Properties and Shielding Gas on Molten Pool Formation during Continuous Laser Welding of AZ91 Magnesium Alloy. Optics \& Laser Technology, 44, 2459-2468. https://doi.org/10.1016/j.optlastec.2012.03.034

[20] Oussaid, K., El Ouafi, A. and Chebak, A. (2019) Experimental Investigation of Laser Welding Process in Overlap Joint Configuration. Journal of Materials Science and Chemical Engineering, 7, 16-31. https://doi.org/10.4236/msce.2019.73002

[21] Kannatey-Asibu Jr., E. (2009) Principles of Laser Materials Processing. John Wiley \& Sons, Hoboken. https://doi.org/10.1002/9780470459300

[22] Feeley, T. (2001) LIA Handbook of Laser Materials Processing. Laser Institute of America, Orlando. 